\title{
More Guidelines than states: variations in U.S. lead screening and management guidance and impacts on shareable CDS development
}

\author{
Jeremy J. Michel ${ }^{1,2,3^{*}}$ D, Eileen Erinoff ${ }^{3}$ and Amy Y. Tsou ${ }^{3,4}$
}

\begin{abstract}
Background: Pediatric lead exposure in the United States (U.S.) remains a preventable public health crisis. Shareable electronic clinical decision support (CDS) could improve lead screening and management. However, discrepancies between federal, state and local recommendations could present significant challenges for implementation.

Methods: We identified publically available guidance on lead screening and management. We extracted definitions for elevated lead and recommendations for screening, follow-up, reporting, and management. We compared thresholds and level of obligation for management actions. Finally, we assessed the feasibility of development of shareable CDS.

Results: We identified 54 guidance sources. States offered different definitions of elevated lead, and recommendations for screening, reporting, follow-up and management. Only 37 of 48 states providing guidance used the Center for Disease Control (CDC) definition for elevated lead. There were 17 distinct management actions. Guidance sources indicated an average of 5.5 management actions, but offered different criteria and levels of obligation for these actions. Despite differences, the recommendations were well-structured, actionable, and encodable, indicating shareable CDS is feasible.

Conclusion: Current variability across guidance poses challenges for clinicians. Developing shareable CDS is feasible and could improve pediatric lead screening and management. Shareable CDS would need to account for local variability in guidance.
\end{abstract}

Keywords: Lead Screening, Lead poisoning, Clinical decision support, Geographic variation in care

\section{Introduction}

Pediatric lead exposure in the United States (U.S.) remains a preventable public health crisis with farreaching consequences $[1,2]$. Even low levels of lead have been associated with learning disabilities and Attention Deficit Hyperactivity Disorder (ADHD) [3]. In 2012, the CDC (along with other organizations) changed the definition for elevated lead from $\geq 10 \mu \mathrm{g} / \mathrm{dL}$ to $\geq 5 \mu \mathrm{g} /$

\footnotetext{
*Correspondence: michelj@email.chop.edu

'Department of Biomedical and Health Informatics, The Children's Hospital of Philadelphia, 2716 South Street, Philadelphia, PA 19146, USA

${ }^{2}$ Department of Pediatrics, Perelman School of Medicine at the University of Pennsylvania, Philadelphia, PA 19146, USA

Full list of author information is available at the end of the article
}

$\mathrm{dL}$, selecting this reference point based on the based on the 97.5th percentile of the BLL distribution in US children aged 1-5 years [4]. Recent lapses in preventive measures have exposed numerous children to elevated lead, with health consequences yet to be determined [5]. As recently as 2016, the Centers for Disease Control (CDC) estimated that 500,000 children tested positive for elevated lead [6]. Preventing pediatric lead exposure is particularly critical, given the potential for lifelong cognitive and behavioral problems $[3,7,8]$.

Detecting and mitigating environmental lead exposure remains the only effective way to protect children. The burden for prevention lies primarily on public health

(c) The Author(s). 2020 Open Access This article is distributed under the terms of the Creative Commons Attribution 4.0 International License (http://creativecommons.org/licenses/by/4.0/), which permits unrestricted use, distribution, and reproduction in any medium, provided you give appropriate credit to the original author(s) and the source, provide a link to the Creative Commons license, and indicate if changes were made. The Creative Commons Public Domain Dedication waiver (http://creativecommons.org/publicdomain/zero/1.0/) applies to the data made available in this article, unless otherwise stated. 
departments, implementation of policies by local organizations, and health care providers responsible for screening [9]. However, adherence to screening requirements remains surprisingly low [10, 11]: roughly $40 \%$ of Medicaid-enrolled children do not receive screening, despite being mandated to do so through the Early Periodic Screening Diagnostic and Testing (EPSDT) program [6]. Overall, low income and minority children remain at higher risk of lead exposure [6].

Guideline-based clinical decision support (CDS) interventions represent a promising strategy for improving care, and can improve guideline adherence [12-14]. CDS, at its most basic level, includes any tool or system designed to help clinicians make decisions [15]. Frequent examples include documentation templates, order sets, computerized order entry [15]. Ideally, shareable guideline based CDS could allow organizations to use one of these tools or systems developed externally, which could be customized for their local environment without investing the considerable resources [16, 17]. However, creating shareable CDS which could be deployed across different geographic areas requires prospective developers to 1) assess if recommended actions could be expressed logically in a formalized machine readable format and 2) identify existing differences in recommended actions for lead screening/management across guidelines $[16,18-21]$. Significant discrepancies in recommendations across guidance sources could present a challenge for CDS authors. For instance, if one state recommends screening children based on zip code of residence while another recommends testing based on the location of a physician's practice, this could result in over and under testing of children receiving care across state lines.

Prior work has examined differences in screening guidelines between states [22]; however, no work has explored the range of recommendations for outpatient management of elevated lead in pediatric populations. Ensuring children with elevated lead receive appropriate interventions is critical to addressing clinical consequences of lead toxicity, but also for identifying environmental sources. CDS offers a tool for improving lead screening and management adherence. To lay the groundwork for developing a shareable CDS, we reviewed publically available guidance for U.S. clinicians. Specifically, our goals were to 1) describe similarities and differences across recommendations for lead screening and management in children, and 2) assess feasibility of converting recommendation statements to CDS and customizing CDS for local guidance, and 3) identify factors that enable or pose significant barriers to the development of shareable CDS. As the CDC provides funding to states for lead screening and management programs, we also considered whether guidance from states receiving CDC funding provided more comprehensive screening and management recommendations [23].

\section{Methods}

\section{Identification of Lead guidance}

We evaluated lead guidance documents provided by all state public health departments and counties funded by the Centers for Disease Control (CDC) [23]. The CDC provides links to all state health departments' lead pages regardless of whether they receive $\mathrm{CDC}$ funding and to the lead pages of counties' health departments that receive funding. For this project, we grouped the District of Columbia with states for analysis. For CDC links that were broken, we used standard web searches to identify the guidance documents from state health departments.

A professional medical librarian performed a supplementary search for additional lead screening and management guidance within Embase, PubMed, ERIC, and CINAHL. Search strategies were customized for each database and included both controlled vocabulary terms and keywords. These keywords also informed the Google grey literature search. Search concepts included lead poisoning, elevated lead, management, treatment, therapy, guidelines, white papers, parameters, pathways, consensus, algorithm, and regulations. After reviewing documents to identify the breadth of recommendations contained in publically available guidance, we defined key elements for abstraction. These key elements included definitions of elevated lead levels (ELL), screening mandates, reporting requirements, clinical management, and follow-up schedule.

\section{Data abstraction}

We designed a data abstraction tool using REDCap [24]. We abstracted information about guidance sources (e.g. publication year), elevated lead definition, screening, reporting, follow-up, and management recommendations. Levels of obligation for each clinical recommendation were determined using a deontic terminology framework [25]. The level of obligation classification system includes three categories (must, should, or consider) corresponding to the expectation for clinicians to carry out a given recommendation. For example, the expectation would be for clinicians to perform all must recommendations, while a consider recommendation might factor in patient preferences. Due to the rarity of must recommendations, we grouped should and must levels of obligation for analysis. Thus, all recommendations were mapped to two levels of provider obligation: consider and should [25].

For each recommendation we identified 1) intervention action, 2) threshold for physicians to consider (option "may") performing the intervention, and 3) threshold for physicians being obligated ("should" or "must") to perform the intervention. For follow-up lead testing, we identified test intervals between initial and confirmatory testing, early monitoring tests and late monitoring tests. Data were abstracted by one author and reviewed for accuracy by another member of the team. 


\section{Analysis}

We assessed whether receiving CDC funding or recent updating of guidance was associated with number of recommendation statements. We also investigated whether states having mandatory reporting or universal screening was associated with particular recommendations (e.g. recommendations for referral to early intervention).

Finally, we considered which discrete concepts across guidelines would require encoding to develop CDS. Concepts were categorized as decision variables or actions [26]. We selected appropriate standard clinical terminologies to represent each concept and identified barriers to identification of decision variables within the electronic health record (EHR) and executability of actions within the EHR.

All statistical tests were performed in Stata 13.1 (StataCorp LP). We tested for association between CDC funding, guidance publication date and cut-off values for elevated lead using Fisher's exact test. We used the Mann-Whitney test to assess whether CDC funding was associated with number of distinct recommendations made by each guidance source.

\section{Results}

Of 51 state public health departments, 48 provided at least minimal guidance on lead screening or management. For 3 states (Arkansas, North Dakota, Wyoming) we were unable to identify any form of publically available guidance for clinicians on lead screening or management.

Thirty-nine states and the District of Columbia receive funding from the $\mathrm{CDC}$, while 11 states receive no funding. In addition, the CDC website linked to 11 city/ county health department administered lead programs receiving CDC funding. Only 2 of 11 (New York City [27-29] and Philadelphia [30, 31]) included lead specific screening and management guidance and were included in our analysis. The other 9 counties received funding for activities related to decreasing lead burden (e.g., for patient evaluation services and/or home inspection services), but did not alter or supplement state provided clinical guidance and were therefore excluded from our analysis.

Supplemental searches identified additional lead screening and management guidance from 4 professional societies/government agencies: the American Academy of Pediatrics (AAP) [7, 32-34], the Center for Medicare and Medicaid Services (CMS) [35, 36], the CDC [37, 38], and the Pediatric Environmental Health Specialty Unit (PEHSU) [39]. In total, we identified 54 guidance sources published between 2008 and 2018 for inclusion: 48 state, 2 city/county, and 4 professional society/government agency (Table 1).
Table 1 Guidance Source Summary Data

\begin{tabular}{|c|c|}
\hline Attribute & Sources examined (\#) \\
\hline Publication (year) ${ }^{a}$ & 54 \\
\hline$\cdot<2012$ & $\cdot 7$ \\
\hline$\cdot \geq 2012$ & $\cdot 45$ \\
\hline - No year ${ }^{b}$ & $\cdot 2$ \\
\hline Definition of ELL & 54 \\
\hline$\cdot \leq 3 \mu \mathrm{g} / \mathrm{dL}$ & $\cdot 1$ \\
\hline$\cdot \leq 5 \mu \mathrm{g} / \mathrm{dL}$ & $\cdot 43$ \\
\hline$\cdot \leq 10 \mu \mathrm{g} / \mathrm{dL}$ & $\cdot 10$ \\
\hline Screening ${ }^{c}$ & 54 \\
\hline - Targeted & $\cdot 35$ \\
\hline - Universal & $\cdot 18$ \\
\hline - Not Addressed & $\cdot 1$ \\
\hline $\begin{array}{l}\text { Reporting } \\
\text { (for states and District of Columbia only) }\end{array}$ & 51 \\
\hline - Mandated All Results & $\cdot 43$ \\
\hline - Mandated ELL Only & $\cdot 7$ \\
\hline - Undefined & $\cdot 1$ \\
\hline Clinical Management & 54 \\
\hline - Provides Management Guidance & $\cdot 43$ \\
\hline - No Management Guidance & $\cdot 11$ \\
\hline Follow Up & 54 \\
\hline - Provides Follow Up Guidance & $\cdot 40$ \\
\hline - No Follow Up Guidance & $\cdot 14$ \\
\hline
\end{tabular}

${ }^{a}$ The AAP published a revised ELL in 2012, which we used as a cutoff for source evaluation

${ }^{b}$ Missouri and Nevada guidance sources lacked publication dates, but documents referenced in these sources indicate these policies were updated or reviewed during or after 2011 for Missouri and circa 2008 for Nevada 'Does not include NY city guidance as it does not differ from NY state guidance

\section{Definition of elevated Lead}

All professional societies and government organizations defined elevated lead as $\geq 5 \mu \mathrm{g} / \mathrm{dL}$, aligning with the CDC definition. However, definitions of ELL differed across states (Table 2). Of states providing guidance $(n=48)$, definitions of ELL ranged from 3 to $10 \mu \mathrm{g} / \mathrm{dl}$, with the majority ( $55 \%, n=37$ ) using the $\geq 5 \mu \mathrm{g} / \mathrm{dL}$ cutoff. Notably, New York City specified a $\geq 5 \mu \mathrm{g} / \mathrm{dL}$ ELL threshold which differed from New York State's definition of $\geq 10 \mu \mathrm{g} / \mathrm{dL}$. Conversely, Philadelphia's threshold (ELL as $\geq 5 \mu \mathrm{g} / \mathrm{dL}$ ) was consistent with Pennsylvania state guidance.

Receiving CDC funding was not associated with adopting the CDC's definition of ELL $(\geq 5 \mu \mathrm{g} / \mathrm{dL})$ or an even more stringent definition (e.g. $>3 \mu \mathrm{g} / \mathrm{dL}),(p=1)$. However, older guidance (published prior to 2012) was associated with using the higher ELL threshold ( $p=0.001)$. Only 4 states with guidance updated after 2012 
Table 2 Definitions of ELL for 50 US States and District of Columbia

\begin{tabular}{|c|c|}
\hline $\begin{array}{l}\text { ELL Definition }(N= \\
\text { 51) }\end{array}$ & States \\
\hline $\begin{array}{l}\text { No level specified }{ }^{a} \\
\text { (3) }\end{array}$ & Arkansas [40], North Dakota [41], Wyoming [42] \\
\hline $\begin{array}{l}\text { Lead Level } \geq 3 \mu \mathrm{g} / \mathrm{dL} \\
\text { (1) }\end{array}$ & New Hampshire $[43,44]$ \\
\hline $\begin{array}{l}\text { Lead Level } \geq 5 \mu \mathrm{g} / \mathrm{dL}^{\mathrm{b}} \\
\text { (37) }\end{array}$ & $\begin{array}{l}\text { Alabama [45], Alaska [46], Arizona [47, 48], California } \\
\text { [49, 50], Colorado [51, 52], Connecticut [53, 54], } \\
\text { District of Columbia [55, 56], Georgia [57-59], } \\
\text { Hawaii [60, 61], Idaho [62, 63], Illinois [64, 65], lowa } \\
\text { [66, 67], Kentucky [68, 69], Louisiana [70-72], Maine } \\
\text { [73, 74], Maryland [75], Massachusetts [76-79], } \\
\text { Michigan [80, 81], Minnesota [82, 83], Mississippi } \\
\text { [84, 85], Montana [86], Nebraska [87, 88], New } \\
\text { Mexico [89], North Carolina [90], Ohio [91, 92], } \\
\text { Oklahoma [93, 94], Oregon [95, 96], Pennsylvania } \\
\text { [97], Rhode Island [98, 99], South Carolina [100], } \\
\text { South Dakota [101, 102], Tennessee [103], Texas } \\
\text { [104, 105], Vermont [106, 107], Virginia [108-110], } \\
\text { Washington [111-113], Wisconsin [114, 115] }\end{array}$ \\
\hline
\end{tabular}

'Lead is included as a 'reportable disease' but no ELL threshold is defined and no other guidance is given

${ }^{\mathrm{b}}$ Montana does not provide screening guidance, but ELL is defined in the 'reportable disease' list when $\geq 5 \mu \mathrm{g} / \mathrm{dL}$

'New York City defines ELL as $\geq 5 \mu \mathrm{g} / \mathrm{dL}$, however the rest of New York State uses ELL as $\geq 10 \mu \mathrm{g} / \mathrm{dL}$

continued to use the $10 \mu \mathrm{g} / \mathrm{dL}$ threshold at the time of our analysis (New Jersey, Delaware, Indiana, and Utah).

\section{Screening}

Universal screening was recommended by 18 of 54 (33\%) guidance sources (CMS for Medicaid recipients, PEHSU, 14 states, the District of Columbia, and the city of Philadelphia [the state of Pennsylvania recommends targeted screening]). Of 18 entities recommending universal screening, the majority $(n=15)$ recommended 2 screenings. The remaining 3 states (Delaware, Massachusetts, and Idaho) recommended 1, 3, and 5 screenings, respectively. With the exception of Montana (which only directs clinicians to the CDC for general guidance), all remaining guidance recommended targeted screening.

\section{Reporting requirements}

We assessed reporting requirements for all 50 states and the District of Columbia. The majority $(n=43)$ mandated reporting of all lead results (regardless of level). For 7 states, reporting was mandated only when lead levels exceeded particular thresholds (greater than $2.3 \mu \mathrm{g} / \mathrm{dL}$, $5 \mu \mathrm{g} / \mathrm{dL}$, or $10 \mu \mathrm{g} / \mathrm{dL}$ ). For one state (Nevada) we could not identify any reporting requirement after an extensive web search, a finding also reported by other investigators [22].

The interval of time permitted between testing and reporting results to a locality varied between states and by lead level. Some states had different reporting requirements for elevated lead vs. normal results. In some cases, reporting requirements within states differed by county. In some cases, states specified that levels above a certain $\mu \mathrm{g} / \mathrm{dL}$ should be reported to a county health department instead of, or in addition to, the state health department. Many states already supported or required electronic result submission.

\section{Clinical Management}

Of 54 guidance sources, 43 included recommendations for clinical management and care. We identified 17 distinct management recommendations (Table 3). On average, each guidance source indicated 5.5 identifiable distinct management recommendations (range 1-13). Many sources of guidance contained some similar recommendations (on average, a recommendation appeared in 13 guidance sources). Surprisingly, no recommendation was included across all guidance sources. The most common management recommendations were for inperson home inspection $(n=33)$, lead avoidance education $(n=32)$, and nutritional counseling $(n=25)$.

The lead level for clinicians to perform actions varied with regard to trigger thresholds and level of obligation (Table 3). For instance, of 33 guidance sources recommending an in-person home inspection, 6 recommended this intervention for all lead testing $\geq 5 \mu \mathrm{g} / \mathrm{dL}$, while 7 only recommended an inspection for lead levels $\geq 20 \mu \mathrm{g} /$ $\mathrm{dL}$. One state recommended clinicians consider iron testing at $\geq 5 \mu \mathrm{g} / \mathrm{dL}$ and another state recommended iron testing should happen at $\geq 10 \mu \mathrm{g} / \mathrm{dL}$. On a few occasions, states provided both a consider and should threshold for the same clinical management activity. For example, a guidance source recommended clinicians consider abdominal radiograph at $\geq 15 \mu \mathrm{g} / \mathrm{dL}$, but should obtain one at levels $\geq 45 \mu \mathrm{g} / \mathrm{dL}$ [49]. Receiving CDC funding was not associated with higher number of distinct recommendations $(p=0.2)$.

\section{Follow-up testing}

Forty (of 54) guidance sources addressed follow up lead testing (after initial screening) with confirmatory testing and/or monitoring. All states addressing elevated levels from capillary testing recommended confirmation with venous tests. Many states recommended confirmation for any result (capillary or venous) between $5 \mu \mathrm{g} / \mathrm{dL}$ and $19 \mu \mathrm{g} / \mathrm{dL}$ before making a diagnosis of elevated lead or initiating management. Intervals for confirmatory testing varied widely, ranging from $24 \mathrm{~h}$ to 3 months, depending on lead level and location of testing.

With regard to monitoring, we again found significant differences across recommendations depending on specimen type (capillary or venous), previous lead result, and lead result trends over time. Most guidance sources 
Table 3 Childhood Lead Management Recommendations

\begin{tabular}{|c|c|c|c|c|c|c|c|c|c|}
\hline \multirow[t]{2}{*}{$\begin{array}{l}\text { Management Recommendations (\# of entities } \\
\text { recommending an action in descending frequency) }\end{array}$} & \multicolumn{9}{|c|}{$\begin{array}{l}\text { Lead level thresholds to perform clinical actions }(\mu \mathrm{g} / \mathrm{dL})^{\mathrm{a}} \\
\text { (\# of entities recommending, cumulative by threshold) }\end{array}$} \\
\hline & $\geq 0$ & $\geq 3$ & $\geq 5$ & $\geq 10$ & $\geq 15$ & $\geq 20$ & $\geq 25$ & $\geq 45$ & $\geq 70$ \\
\hline In person home inspection (33) & - & - & 6 & 18 & 26 & 33 & $*$ & * & * \\
\hline Lead avoidance education (32) & 17 & 18 & 31 & 32 & * & * & * & * & * \\
\hline Nutrition counseling (25) & 4 & 5 & 22 & 25 & * & * & * & * & * \\
\hline Iron testing (24) & - & - & 11 & 15 & 18 & 24 & * & * & * \\
\hline Hospitalization (24) & - & - & - & - & - & - & 1 & 9 & 24 \\
\hline Abdominal X-Ray (16) & - & - & 3 & 3 & 5 & 10 & 10 & 16 & * \\
\hline Refer to social work (14) & - & - & 3 & 12 & 12 & 14 & * & * & * \\
\hline Test family members (12) & - & 1 & 8 & 11 & 11 & 12 & * & * & * \\
\hline Refer to Women, Infants, and Children (WIC) or nutrition (10) & - & - & 5 & 7 & 8 & 10 & * & * & * \\
\hline In office exposure assessment (9) & - & - & 6 & 7 & 9 & * & * & * & * \\
\hline Start iron or vitamin with iron (8) & - & - & 6 & 7 & 7 & 8 & * & * & * \\
\hline Refer to early intervention (8) & - & - & 2 & 6 & 6 & 8 & * & * & * \\
\hline File/Contact social services (8) & - & - & 2 & 5 & 5 & 6 & 6 & 8 & * \\
\hline Refer to a lead clinic (7) & - & - & 1 & 1 & 1 & 3 & 3 & 7 & * \\
\hline Phone exposure assessment (3) & - & - & 3 & * & * & * & * & * & * \\
\hline Refer to medical specialty (2) & - & - & 1 & 1 & 1 & 1 & 1 & 2 & * \\
\hline Add ELL to problem list (1) & - & - & 1 & * & * & * & * & * & * \\
\hline
\end{tabular}

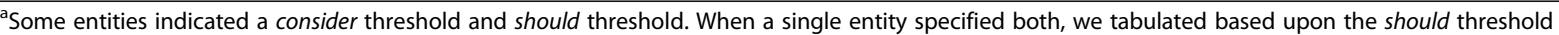

${ }^{\mathrm{b}} \mathrm{A} *$ indicates that all entities with this recommendation have been accounted for at a lower threshold

(82.5\%, 33 of 40) offered different guidance for capillary compared to venous results. Sixty percent $(24$ of 40$)$ of guidance sources included recommendations that changed based on lead level trends over time. Variability was high for lower lead levels (e.g. 5-20 $\mu \mathrm{g} / \mathrm{dl}$ ), but similar for patients with ELL $\geq 45 \mu \mathrm{g} / \mathrm{dl}$. Some guidance statements provided age specific recommendations (older children (age $\geq 6$ ) and adults). No guidance sources cited evidence to support follow up testing beyond a general reference to $\mathrm{CDC}$ or AAP guidance.

\section{Considerations for CDS development}

We identified 20 discreet actions addressing screening (1), reporting (1), management (17), and follow-up (1). The logic for most recommendations was clear, unambiguous, and contained simple executable logic. All recommendations for lead screening and management were triggered by 5 patient and environment factors: patient age, office location (state), zip code of office, insurance type, and lead result history. These data are typically accessible within EHRs and sufficiently structured to permit use. Thus, we anticipate using parameters within the CDS Authoring Tool would allow for creation of practice specific rules (i.e. CDS reflecting local guidance). Furthermore, nearly all specified actions $(n=18)$ were directly related to the patient (and thus, amenable to implementation and adherence measurement). Only two recommendations did not directly involve the patient (recommendations for home testing and testing of family members). For these recommendations it was unclear who the actor should be (e.g. clinician or department of health representative).

Many recommendations $(n=10)$ required information that would need to be specified locally (e.g. fax number for early intervention, supplemental questions to ask on telephone assessment), but were otherwise executable. Thus, our analysis suggests current recommendations are amenable for conversion to CDS.

\section{Discussion}

\section{Main findings of this study}

We found numerous differences across guidance sources for screening and management of children with ELL. Eleven states do not use the CDC's definition of elevated lead, and states offer variable guidance for what care children with ELL should receive. Only reporting requirements are relatively uniform across all states. These differences suggest any CDS intervention would require customization for local guidance, as many health systems span multiple localities. However, despite variability, recommendations were clear, concise, based upon a limited set of patient factors, and overwhelmingly executable suggesting they could translate well into effective CDS [116-118]. 


\section{What is already known on this topic}

CDS has been previously developed to facilitate adherence to local guidance for lead screening and management. Our institution, for example, has incorporated initial lead screening within the well child care set as an optional order for relevant age groups. This basic CDS originally used only the most basic patient characteristics (age and insurance type) to determine for which patient it should be displayed. One local clinical site augmented this to support city guidance that differed from guidance across the rest of the network, and increased completed screening rates within the first 6 months from 73 to $81 \%$ and ordering rates from 85 to $95 \%$. However, despite being effective, it has been difficult to share due to differences in applicable guidance, laboratory order options, and concerns about impact on workflow.

CDS, based upon a disseminated model, has proven an effective tool for addressing other pediatric public health problems. For example, CDS for immunizations has improved immunization rates [119-121]. While these immunization recommendations are the same across states, they are constantly updated. To address this, a shareable resource for immunization and CDS implementation was developed (CDSi), which allows local sites to develop and test immunization rules to ensure their patients are being provided the most appropriate care [122]. The team responsible for CDSi handles interpreting updates to immunization recommendation and encoding the computer logic necessary to produce the CDS. This allows organizations more time to focus on how best to incorporate these changes into workflow and to test changes without needing to reinvent the wheel. This disseminated CDS model demonstrates that shareable CDS initiatives can be used to address public health conditions.

\section{What this study adds}

While geographic differences in lead exposure and competing priorities for resources may impact how localities decide to screen and manage childhood lead exposure [123, 124], the level of variability in screening and management guidelines is surprising. Differences with regard to universal versus targeted screening are understandable as local differences in environmental exposure result in difference risk-benefit ratios. However, state to state differences in what constitutes elevated lead and what management children should receive are problematic.

We found that receiving CDC funding was not associated with adopting current $\mathrm{CDC}$ definitions of elevated lead. However, older guidance (published before the CDC changed the ELL threshold) was more likely to use higher ELL thresholds. Comparison to prior work suggests more states have adopted $\geq 5 \mu \mathrm{g} / \mathrm{dL}$ threshold to define elevated lead since 2017, with only 10 states continuing to use $10 \mu \mathrm{g} / \mathrm{dL}$ threshold [22].

We found developing shareable CDS would be feasible despite this variability based on well written, actionable, and encodable recommendations. We anticipate healthcare organizations or health departments looking to sponsor CDS development for lead screening and management would need to overcome four challenges: 1) high volume of recommendations; 2) small differences between recommendations (i.e. handling the complex follow-up schedule); and 3) location specific concerns (e.g., regional risk factors for exposure) and 4) access to local resources (e.g. referral to local lead clinics and home inspection agencies). Cloud based or API driven solutions could work and have been used in the past for CDS [20, 21, 125]. However, new innovations in shareable CDS, including the Clinical Query Language [126], could better support CDS for lead screening and management through the embedded 'parameters' function, which was specifically developed to address this need for inter-organization variation [127].

\section{Limitations}

As this project was aimed at describing the breadth of recommendations to inform CDS development, our efforts to identify recommendations was limited to web searches. Since we did not contact health departments directly, if websites were not regularly updated, our information may be inaccurate or outdated. However, these concerns are applicable to all web-search based research, and not specific to this project. As data abstraction from source documents was performed by a single abstractor, it is possible some recommendations were read or misinterpreted. However, this would have limited impact on our analysis, as a missed recommendation would likely exist in other guidance sources and have therefore have been evaluated for impact on shareable CDS development.

\section{Next steps}

Given our findings and the large at-risk population, we believe developers should move quickly to develop and implement shareable CDS for lead screening and management. As a continuation of this effort, we are using the National Library of Medicine's Value Set Authority Center to disseminate encodable representations of relevant clinical concepts identified during this project [128]. Also, our findings have been used to improve the alignment of current CDS at the Children's Hospital of Philadelphia for lead screening with city, state, and national recommendations. We hope to demonstrate that adaptation of recommendations for lead screening and management can improve detection and management of lead in children and to study the spread of this 
intervention within and beyond the institution. Preliminary results suggest locally deployed CDS has significantly improved adherence to lead screening guidelines.

\section{Conclusions}

Significant important differences across guidance for lead screening, reporting, management, and follow-up in the U.S. exists. These differences present both challenges and opportunities for CDS interventions. Although absence of a standardized definition of elevated lead and management recommendations poses challenges for the development of shareable CDS, this is balanced by well structured, actionable, and encodable recommendations. Although development of consensus regarding diagnosis of elevated lead and general management guidelines would be preferable, innovations in the field of shareable CDS can support local implementations when consensus among recommendation authors cannot be obtained.

\section{Abbreviations}

AAP: American Academy of Pediatrics; ADHD: Attention Deficit Hyperactivity Disorder; CDC: Center for Disease Control and Prevention; CDS: Clinical decision support; CHOP: Children's Hospital of Philadelphia; CMS: Center for Medicare and Medicaid Services; EHR: Electronic Health Record; ELL: Elevated Lead Level; PEHSU: Pediatric Environmental Health Specialty Unit

\section{Acknowledgements}

None.

\section{Authors' contributions}

JJM performed the data collection, contributed to the analyses and interpretation of the data, developed the electronic decision support tools, drafted significant portions of the initial manuscript, reviewed and revised the manuscript, and approved the final manuscript as submitted. EE performed the systematic literature review to identify relevant supplemental guidance sources, critically reviewed the manuscript, and approved the final manuscript as submitted. AYT contributed to the conceptualization and design of the study, participated in data analysis and data validation, drafted portions of the manuscript, and approved the final manuscript as submitted.

\section{Funding}

The authors have no financial relationships relevant to this article to disclose. This study was supported by The Children's Hospital of Philadelphia and by ECRI Institute. These funding institutions provide salary support to the authors involved in this study and cover works expenses related to investigative activities including data collection, analysis, interpretation, and publication.

\section{Availability of data and materials}

The datasets used and/or analyzed during the current study are available from the corresponding author on reasonable request. Please contact jmichel@ecri.org if you are interested in access to the data used in this study.

\section{Ethics approval and consent to participate}

As data is publically available, ethics approval and consent was not required.

\section{Consent for publication}

Not applicable.

\section{Competing interests}

The authors declare that they have no competing interests.

\section{Author details}

'Department of Biomedical and Health Informatics, The Children's Hospital of Philadelphia, 2716 South Street, Philadelphia, PA 19146, USA. ${ }^{2}$ Department of Pediatrics, Perelman School of Medicine at the University of Pennsylvania,
Philadelphia, PA 19146, USA. ${ }^{3}$ ECRI Institute Center for Clinical Evidence and Guidelines, Plymouth Meeting, PA 19462, USA. ${ }^{4}$ Michael J Crescenz Veterans Affairs Medical Center, Philadelphia, PA 19104, USA.

Received: 1 November 2019 Accepted: 15 January 2020

Published online: 29 January 2020

\section{References}

1. Shah KK, Oleske JM, Gomez HF, et al. Blood Lead concentrations of children in the United States: a comparison of states using two very large databases. J Pediatr. 2017;185:218-23. https://doi.org/10.1016/j.jpeds.2017.01.059 PubMed PMID: 28258736. Epub 2017/03/05. eng.

2. Benfer E. Contaminated childhood: the chronic Lead poisoning of lowincome children and communities of color in the United States. Health Affairs Blog. 2017. https://doi.org/10.1377/hblog20170808.061398.

3. Vorvolakos T, Arseniou S, Samakouri M. There is no safe threshold for lead exposure: Alpha literature review. Psychiatriki. 2016;27(3):204-14 PubMed PMID: 27837574. Epub 2016/11/12. eng.

4. Advisory Committee on Childhood Lead Poisoning Prevention. Low Level Lead Exposure Harms Children: A Renewed Call for Primary Prevention. Atlanta: Centers for Disease Control and Prevention; 2012.

5. Kennedy C, Yard E, Dignam T, et al. Blood Lead Levels Among Children Aged <6 Years - Flint, Michigan, 2013-2016. MMWR Morb Mortal Wkly Rep. 2016;65(25):650-4. https://doi.org/10.15585/mmwr.mm6525e1 PubMed PMID: 27359350. Epub 2016/07/01. eng.

6. Morley R, Lenhart A, Illa G, Brown MJ; 10 policies to prevent and respond to childhood Lead exposure an assessment of the risks communities face and key federal, state, and local solutions. 2017. PEW Charitable Trust.

7. Committee on Environmental Health. Lead Exposure in Children: Prevention, Detection, and Management. Pediatrics. 2005;116(4):1036-46. https://doi.org/10.1542/peds.2005-1947.

8. Dapul H, Laraque D. Lead poisoning in children. Adv Pediatr Infect Dis. 2014;61(1):313-33. https://doi.org/10.1016/j.yapd.2014.04.004 PubMed PMID: 25037135. Epub 2014/07/20. eng.

9. Nussbaumer-Streit B, Yeoh B, Griebler U, et al. Household interventions for preventing domestic lead exposure in children. Cochrane Database Syst Rev. 2016;10:CD006047. https://doi.org/10.1002/14651858.CD006047.pub5 PubMed PMID: 27744650. Epub 2016/11/02. eng.

10. Keeshan B, Avener C, Abramson A, et al. Barriers to pediatric lead screening: implications from a web-based survey of Vermont pediatricians. Clin Pediatr. 2010;49(7):656-63. https://doi.org/10.1177/0009922809360926 PubMed PMID: 20150211. Epub 2010/02/13. eng.

11. Knighton AJ, Payne NR, Speedie S. Lead testing in a pediatric population: Underscreening and problematic repeated tests. J Public Health Manage Pract. 2016;22(4):331-7. https://doi.org/10.1097/phh.0000000000000344 PubMed PMID: 26418307. Epub 2015/09/30. eng.

12. Heselmans A, Van de Velde S, Donceel P, et al. Effectiveness of electronic guideline-based implementation systems in ambulatory care settings - a systematic review. Implement Sci. 2009;4:82. https://doi.org/10.1186/17485908-4-82 PubMed PMID: 20042070. PMCID: 2806389. Epub 2010/01/01. eng.

13. Forrest $C B$, Fiks $A G$, Bailey $L C$, et al. Improving adherence to otitis media Guidelines with clinical decision support and physician feedback. Pediatrics. 2013;11:2013. https://doi.org/10.1542/peds.2012-1988.

14. Utidjian LH, Hogan A, Michel J, et al. Clinical Decision Support and Palivizumab: A Means to Protect from Respiratory Syncytial Virus. Appl Clin Inform. 2015;6(4):769-84. https://doi.org/10.4338/aci-2015-08-ra-0096 PubMed PMID: 26767069. PMCID: 4704044. Epub 2016/01/15. eng.

15. Shortliffe EH, Cimino JJ (Eds). Biomedical informatics: Computer Applications in Health Care and Biomedicine. Springer; 2006.

16. Dixon $B E$, Simonaitis $L$, Goldberg $H S$, et al. A pilot study of distributed knowledge management and clinical decision support in the cloud. Artif Intell Med. 2013;59(1):45-53. https://doi.org/10.1016/j.artmed.2013.03.004 PubMed PMID: 23545327. Epub 2013/04/03. eng.

17. Kawamoto K, Jacobs J, Welch BM, et al. Clinical information system services and capabilities desired for scalable, standards-based, service-oriented decision support: consensus assessment of the Health Level 7 clinical decision support Work Group. AMIA Annu Symp Proc. 2012;2012:446-55 PubMed PMID: 23304315. PMCID: 3540445. Epub 2013/01/11. eng.

18. Berges I, Bermudez J, Illarramendi A. Toward semantic interoperability of electronic health records. IEEE Trans Inf Technol Biomed. 2012;16(3):424-31. 
https://doi.org/10.1109/titb.2011.2180917 PubMed PMID: 22217917. Epub 2012/01/06. eng.

19. Fernandez-Breis JT, Maldonado JA, Marcos M, et al. Leveraging electronic healthcare record standards and semantic web technologies for the identification of patient cohorts. J Am Med Inform Assoc. 2013;20(e2):e28896. https://doi.org/10.1136/amiajnl-2013-001923 PubMed PMID: 23934950. PMCID: 3861938. Epub 2013/08/13. eng.

20. Marcos M, Maldonado JA, Martinez-Salvador B, et al. Interoperability of clinical decision-support systems and electronic health records using archetypes: a case study in clinical trial eligibility. J Biomed Inform. 2013; 46(4):676-89. https://doi.org/10.1016/j.jbi.2013.05.004 PubMed PMID: 23707417. Epub 013/05/28. eng.

21. Mandel JC, Kreda DA, Mandl KD, et al. SMART on FHIR: a standards-based, interoperable apps platform for electronic health records. J Am Med Inform Assoc. 2016. https://doi.org/10.1093/jamia/ocv189 PubMed PMID: 26911829. Epub 2016/02/26. Eng.

22. Dickman J. Children at risk: gaps in state Lead Screening policies. Safer Chemicals, Healthy Families; 2017.

23. Center for Disease Control. State Programs. Atlanta: Center for Disease Control; 2017. Available from: https://www.cdc.gov/nceh/lead/programs/ default.htm Access Date: 2018/12/28

24. Harris PA, Taylor R, Thielke R, et al. Research electronic data capture (REDCap) - a metadata-driven methodology and workflow process for providing translational research informatics support. J Biomed Inform. 2009; 42(2):377-81.

25. Lomotan EA, Michel G, Lin Z, et al. How "should" we write guideline recommendations? Interpretation of deontic terminology in clinical practice guidelines: survey of the health services community. Qual Saf Health Care. 2010;19(6):509-13. https://doi.org/10.1136/qshc.2009.032565 PubMed PMID: 20702437. PMCID: 2982946. Epub 2010/08/13. eng.

26. Shiffman RN, Karras BT, Agrawal A, et al. GEM: a proposal for a more comprehensive guideline document model using XML. J Am Med Inform Assoc. 2000;7:11.

27. Lead Poisoning New York, New York: New York City Department of Health and Mental Hygiene; 2018. Available from: https://www1.nyc.gov/site/doh/ health/health-topics/lead-poisoning-prevention.page Access Date: 2018-1227.

28. Lead Poisoning for Healthcare Providers "New York, New York": New York City Department of Health and Mental Hygiene; 2018. Available from: https://www1.nyc.gov/site/doh/health/health-topics/lead-poisoning-forhealthcare-providers.page Access Date: 2018-12-27.

29. Lead Exposure in Children "New York, New York": New York City Department of Health and Mental Hygiene; 2018. Available from: https:// www1.nyc.gov/assets/doh/downloads/pdf/lead/lead-guidelines-children.pdf Access Date: 2018-12-27.

30. Philadelphia Childhood Lead Poisoning "Philadelphia, Pennsylvania": "City of Philadelphia, Department of Public Health"; 2017. Available from: http:// www.phila.gov/health/childhoodlead/index.html Access Date: 2018-09-01.

31. Guide for Clinicians: Preventing Lead Exposure in Children "Philadelphia, Pennsylvania": "City of Philadelphia, Department of Public Health"; 2017. Available from: http://www.phila.gov/health/pdfs/ChildhoodLead/ Guide\%20for\%20Clinicians_December\%202017\%20update.pdf Access Date: 2018-09-01.

32. Committee on Environmental Health. Screening for Elevated Blood Lead Levels. Pediatrics. 1998;101(6):1072-8. https://doi.org/10.1542/peds.101.6.1072.

33. Council on Environmental Health. Prevention of Childhood Lead Toxicity. Pediatrics. 2016;138(1):e20161493. https://doi.org/10.1542/peds.2016-1493.

34. Council on Environmental Health. Prevention of Childhood Lead Toxicity Correction. Pediatrics. 2017;140(2):e20171490. https://doi.org/10.1542/peds. 2017-1490.

35. Lead Screening Baltimore, MD: Centers for Medicare and Medicaid Services; 2016. Available from: https://www.medicaid.gov/medicaid/benefits/epsdt/ lead-screening/index.html Access Date: 2018-12-27.

36. Coverage of Blood Lead Testing for Children Enrolled in Medicaid and the Children's Health Insurance Program Baltimore, MD: Centers for Medicare and Medicaid Services; 2016. Available from: https:/www.medicaid.gov/ federal-policy-guidance/downloads/cib113016.pdf Access Date: 2018-12-27.

37. What Do Parents Need to Know to Protect Their Children? Atlanta, GA: Centers for Disease Control and Prevention; 2017. Available from: https:// www.cdc.gov/nceh/lead/acclpp/blood_lead_levels.htm Access Date: 2018$12-27$.
38. Recommended Actions Based on Blood Lead Level Atlanta, GA: Centers for Disease Control and Prevention; 2017. Available from: https://www.cdc.gov/ nceh/lead/acclpp/actions_blls.html Access Date: 2018-12-27.

39. Newman N, Binns HJ, Karwowski M, et al. Recommendations on Medical Management of Childhood Lead Exposure and Poisoning. Elk Grove: Pediatric Environmental Health Specialty Units; 2013. Available from: https:// www.pehsu.net/_Library/facts/medical-mgmnt-childhood-lead-exposureJune-2013.pdf Access Date: 2018-12-27

40. The Center for Disease Control and Prevention Lowers the Definition... Arkansas: Arkansas; 2012. Access Date: 2018-12-27.

41. BLOOD LEAD REPORT North Dakota: ND Department of Health; 2014. Available from: https://deq.nd.gov/Forms/AQ/Lead/SFN60104.pdf Access Date: 2018-12-27.

42. Wyoming Department of Health Reportable Diseases and Conditions Wyoming: Wyoming Department of Health; 2018. Available from: https:// health.wyo.gov/wp-content/uploads/2018/01/2018ReportableList.pdf Access Date: 2018-12-27.

43. Healthy Homes and Lead Poisoning Prevention Program New Hampshire: New Hampshire Department of Health and Human Services; 2018. Available from: https://www.dhhs.nh.gov/dphs/bchs/clpp/index.htm Access Date: 2018-12-27.

44. Medical Care Providers New Hampshire: New Hampshire Department of Health and Human Services; 2018. Available from: https://www.dhhs.nh.gov/ dphs/bchs/clpp/medical-providers.htm Access Date: 2018-12-27.

45. Alabama Childhood Lead Poisoning Prevention Project (ACLPPP) Alabama: Alabama Public Health; 2017. Available from: http://www. alabamapublichealth.gov/aclppp/index.html Access Date: 2018-12-27.

46. M. Mui, A. Herman, J. Michel, et al. Obesity Prevention and Management Pathway: The Children's of Philadelphia; 2014. Available from: http://www. chop.edu/clinical-pathway/obesity-prevention-and-management-clinicalpathway

47. Childhood Lead Screening Arizona: Arizona Department Of Health Services; 2016. Available from: https://www.azdhs.gov/documents/preparedness/ epidemiology-disease-contro//lead-poisoning/lead-screening-guide.pdf. Access Date: 2018-12-27.

48. Arizona Dept of Health Services. Lead Poisoning Arizona: ARIZONA DEPARTMENT OF HEALTH SERVICES; 2018. Available from: https://www. azdhs.gov/preparedness/epidemiology-disease-control/lead-poisoning/ index.php. Access Date: 2018-12-27.

49. Childhood Lead Poisoning Prevention Branch, Health Care Providers California: California Department of Public Health; 2017. Available from: https://www.cdph.ca.gov/Programs/CCDPHP/DEODC/CLPPB/Pages/prov. aspx Access Date: 2018-12-27.

50. Occupational Lead Poisoning Prevention, Laboratory requirements for blood lead analysis California: California Department of Public Health; 2017. Available from: https://www.cdph.ca.gov/Programs/CCDPHP/DEODC/OHB/ OLPPP/Pages/LabReq.aspx Access Date: 2018-12-27.

51. Lead Testing Colorado: Colorado Department of Public Health \& Environment; 2018. Available from: https://www.colorado.gov/pacific/ cdphe/lead-testing Access Date: 2018-12-27.

52. For Health Professionals Colorado: Colorado Department of Public Health \& Environment; 2018. Available from: https://www.colorado.gov/pacific/ cdphe/lead-health-professionals Access Date: 2018-12-27.

53. Lead Poisoning Prevention and Control Program Connecticut: Connecticut State Department of Public Health; 2013. Available from: https://portal.ct.gov/DPH/Environmental-Health/Lead-PoisoningPrevention-and-Control/Lead-Poisoning-Prevention-and-Control-Program Access Date: 2018-12-27.

54. Blood Lead Testing Requirements in Connecticut Connecticut: Connecticut State Department of Public Health; 2013. Available from: https://portal.ct.gov/DPH/Environmental-Health/Lead-PoisoningPrevention-and-Control/For-Medical-Providers\#BLL Testing Requirements Access Date: 2018-12-27.

55. Lead-Safe and Healthy Homes District of Columbia: Department of Energy \& Environment; 2017. Available from: https://doee.dc.gov/ leadsafehealthyhomes Access Date: 2018-12-27.

56. Lead Exposure and Healthy Homes: Prevention and Management for Healthcare Providers District of Columbia: Department of Energy \& Environment; 2017. Available from: https://doee.dc.gov/service/leadexposure-and-healthy-homes-prevention-and-management-healthcareproviders Access Date: 2018-12-27. 
57. Healthy Homes and Lead Poisoning Prevention Georgia: Georgia Department of Public Health; 2016. Available from: https://dph.georgia.gov/ healthy-homes-and-lead-poisoning-prevention Access Date: 2018-12-27.

58. Lead Screening, Case Management, Lab Submissions, Reporting Guidelines Georgia: Georgia Department of Public Health; 2016. Available from: https:// dph.georgia.gov/lead-screening-case-management-lab-submissionsreporting-guidelines Access Date: 2018-12-27.

59. Lead Screening Guidelines for Children Georgia: Georgia Department of Public Health; 2016. Available from: https://dph.georgia.gov/lead-screeningguidelines-children Access Date: 2018-12-27.

60. Childhood Lead Poisoning Prevention Hawaii: State of Hawaii, Department of Health; 2018. Available from: http://health.hawaii.gov/cshcn/leadpp/ Access Date: 2018-12-27.

61. New Guidelines: Childhood Lead Poisoning Prevention Hawaii: State of Hawaii, Department of Health; 2018. Available from: https://health.hawaii. gov/cshcn/files/2018/08/DOHCLPPmemoguidelines8-7-18.pdf Access Date: 2018-12-27.

62. Hay WW. Optimizing nutrition of the preterm infant. Zhongguo Dang Dai Er Ke Za Zhi. 2017;19(1):1-21 PubMed PMID: 28100316. Epub 2017/01/20. eng.

63. Lead Idaho: Idaho, Department of Health and Welfare; 2008. Available from: http://healthandwelfare.idaho.gov/Health/EnvironmentalHealth/ IndoorEnvironment/Lead/tabid/941/Default.aspx Access Date: 2018-12-27.

64. Lead Testing \& Case Management Illonois: Illonois, Department of Public Health; 2015. Available from: http://www.dph.illinois.gov/topics-services/ environmental-health-protection/lead-poisoning-prevention/testing-casemanagement Access Date: 2018-12-27.

65. Lead Testing and Case Follow-up Guidelines for Local Health Departments Illonois: Illonois, Department of Public Health; 2015. Available from: http:// dph.illinois.gov/sites/default/files/publications/lead-testing-and-casefollowup-guidelinesfor-local-health-departments-042116.pdf Access Date: 2018-12-27.

66. Lead Poisoning lowa: lowa Department of Public Health Lead Poisoning Prevention Program; 2017. Available from: http://idph.iowa.gov/Portals/1/ userfiles/106/protect_iowa_families_Oct2017.pdf Access Date: 2018-12-27.

67. Physician Guidelines - Childhood Lead Poisoning Prevention lowa: lowa Department of Public Health Lead Poisoning Prevention Program; 2017. Available from: http://idph.iowa.gov/Portals/1/userfiles/197/BEHS/lead\%2 Oresources\%20pdfs/Risk\%20Questionnaire\%2C\%20Blood\%20Lead\%20Test\%2 0Charts\%2C\%20\%26\%20Physicians\%20Guidelines\%20\%289-17\%29.pdf Access Date: 2018-12-27.

68. Lead Program Kentucky: Commonwealth of Kentucky Cabinet for Health and Family Services; 2016. Available from: https://chfs.ky.gov/agencies/dph/ dphps/psb/Pages/lead.aspx Access Date: 2018-12-27.

69. Ainsworth SB, McGuire W. Peripherally inserted central catheters vs peripheral cannulas for delivering parenteral nutrition in neonates. JAMA. 2016;315(23):2612-3. https://doi.org/10.1001/jama.2016.7020 PubMed PMID: 27327804. Epub 2016/06/22. eng.

70. Information for Healthcare and Social Service Professionals Louisiana: Louisiana Department of Health; 2014. Available from: http://ldh.la.gov/ index.cfm/page/3161 Access Date: 2018-12-27.

71. Information for Families and Caregivers Louisiana: Louisiana Department of Health; 2014. Available from: http://ldh.la.gov/index.cfm/page/3162 Access Date: 2018-12-27.

72. Louisiana Healthy Homes and Childhood Lead Poisoning Prevention Program Louisiana: Louisiana Department of Health; 2014. Available from: http://www.ldh.la.gov/assets/oph/Center-PHCH/Center-PH/genetic/LEAD/ NewsandUpdates/ToolkitforProviderandParent20162018finalrevision.pdf Access Date: 2018-12-27.

73. Lee HH, Jung JM, Nam SH, et al. Risk factor analysis of parenteral nutritionassociated cholestasis in extremely low birth weight infants. Acta Paediatrica (Oslo, Norway : 1992). 2016;105(7):e313-9. https://doi.org/10. 1111/apa.13441 PubMed PMID: 27097151. Epub 2016/04/21. eng.

74. Childhood Lead Poisoning - Provider Information Maine: Maine Center for Disease Control \& Prevention, Division of Environmental Health; 2016. Available from: http://www.maine.gov/dhhs/mecdc/environmental-health/ eohp/lead/providers.shtml Access Date: 2018-12-27.

75. Health Care Providers Maryland: Department of the Enviroment; 2016. Available from: http://www.mde.state.md.us/programs/LAND/ LeadPoisoningPrevention/Pages/healthcare.aspx Access Date: 2018-12-27.

76. Childhood Lead Poisoning Prevention Program (CLPPP) Massachusets: Childhood Lead Poisoning Prevention Program (CLPPP); 2017. Available from: https://www.mass.gov/orgs/childhood-lead-poisoning-preventionprogram Access Date: 2018-12-27.

77. Lisanti AJ, Savoca M, Costarino D, et al. Nutrition for Neonates Undergoing Surgery for Congenital Heart Disease: The Children's Hospital of Philadelphia; 2017. Available from: http://www.chop.edu/clinical-pathway/ nutrition-neonates-undergoing-surgery-chd-clinical-pathway

78. Learn about lead screening and reporting requirements Massachusets: Childhood Lead Poisoning Prevention Program (CLPPP); 2017. Available from: https://www.mass.gov/service-details/learn-about-lead-screening-andreporting-requirements Access Date: 2018-12-27.

79. Learn about lead testing in Massachusetts and what a result means for your child Massachusets: Childhood Lead Poisoning Prevention Program (CLPPP); 2017. Available from: https://www.mass.gov/service-details/learn-about-leadtesting-in-massachusetts-and-what-a-result-means-for-your-child Access Date: 2018-12-27.

80. Lead Michigan: Michigan Department of Health and Human Services; 2015. Available from: https://www.michigan.gov/lead Access Date: 2018-12-27.

81. Riskin A, Hartman C, Shamir R. Parenteral nutrition in very low birth weight preterm infants. Isr Med Assoc J. 2015;17(5):310-5 PubMed PMID: 26137659. Epub 2015/07/04. eng.

82. Health Care Professionals Minnesota: Minnesota Department of Health; 2011. Available from: http://www.health.state.mn.us/divs/eh/lead/hcprof/ index.html Access Date: 2018-12-27.

83. Childhood Blood Lead Screening Guidelines for Minnesota Minnesota: Minnesota Department of Health; 2011. Available from: http://www.health. state.mn.us/divs/eh/lead/guidelines/index.html\#screening Access Date: 2018-12-27.

84. Lead Poisoning Prevention Mississippi: Mississippi State Department of Health; 2017. Available from: http://www.msdh.state.ms.us/msdhsite/_ static/41,0,176.html Access Date: 2018-12-27.

85. Lead Poisoning Prevention and Healthy Homes Program Care Coordination Plan Mississippi: Mississippi State Department of Health; 2017. Available from: http://www.msdh.state.ms.us/msdhsite/_static/resources/3083.pdf Access Date: 2018-12-27.

86. Rule: 37.114.203 Montana: Montana Secretary of State; 2017. Available from: http://mtrules.org/gateway/RuleNo.asp?RN=37.114.203 Access Date: 2018$12-27$.

87. Lead Home Page Nebraska: Nebraska Department of Health \& Human Services; 2011. Available from: http://dhhs.ne.gov/publichealth/Pages/ Leadlndex.aspx Access Date: 2018-12-27.

88. Resources for Health Care Professionals Nebraska: Nebraska Department of Health \& Human Services; 2011. Available from: http://dhhs.ne.gov/ publichealth/Pages/LeadHealthcare.aspx Access Date: 2018-12-27.

89. Childhood Lead Poisoning Prevention Program New Mexico: New Mexico Department of Health; 2016. Available from: https://nmhealth.org/about/ erd/eheb/clppp/. Accessed 27 Dec 2018.

90. Childrens Environmental Health North Carolina: NC Department of Health and Human Servuces; 2018. Available from: https://ehs.ncpublichealth.com/ hhccehb/cehu/index.htm Access Date: 2018-12-27.

91. Childhood Lead Poisoning Ohio: Ohio Department of Health; 2014. Available from: https://odh.ohio.gov/wps/portal/gov/odh/know-ourprograms/childhood-lead-poisoning Access Date: 2018-12-27.

92. Medical Management Recommendations Ohio: Ohio Department of Health; 2014. Available from: https://odh.ohio.gov/wps/portal/gov/odh/know-ourprograms/childhood-lead-poisoning/for-healthcare-providers/medicalmanagement-recommendations Access Date: 2018-12-27.

93. Oklahoma Childhood Lead Poisoning Prevention Program Oklahoma: Oklahoma State Department of Health; 2018. Available from: https://www. ok.gov/health/Family_Health/Screening_\&_Special_Services/Oklahoma_ Childhood_Lead_Poisoning_Prevention_Program/index.html Access Date: 2018-12-27.

94. Guidelines for Management of Blood Lead Levels in Children - March 2018 Oklahoma: Oklahoma State Department of Health; 2018. Available from: https://www.ok.gov/health2/documents/LEAD\%20Management\%2 OGuidelines.pdf Access Date: 2018-12-27.

95. Lead Poisoning and Exposure to Lead Oregon: Oregon Health Authority; 2016. Available from: https://www.oregon.gov/oha/ph/ HealthyEnvironments/HealthyNeighborhoods/LeadPoisoning/Pages/index. aspx Access Date: 2018-12-27.

96. Lead Screening Protocols and Questionnaires Oregon: Oregon Health Authority; 2016. Available from: https://www.oregon.gov/oha/PH/ 
HEALTHYENVIRONMENTS/HEALTHYNEIGHBORHOODS/LEADPOISONING/ COUNTYHEALTHDEPARTMENTS/Pages/index.aspx Access Date: 2018-12-27.

97. Childhood Lead Poisoning and Prevention in Pennsylvania Pennsylvania: Pennsylvania Department of Health; 2015. Available from: https://www. health.pa.gov/topics/Documents/Environmental\%20Health/2015\%20Lead\%2 OSurveillance\%20Annual\%20Report.pdf Access Date: 2018-12-27.

98. Franco KA, O'Mara K. Impact of Computerized Provider Order Entry on Total Parenteral Nutrition in the Neonatal Intensive Care Unit. J Pediatr Pharmacol Ther. 2016;21(4):339-45. https://doi.org/10.5863/1551-6776-21.4.339 PubMed PMID: 27713674. PMCID: 5040178. Epub 2016/10/08. eng.

99. Childhood Lead Poisoning Prevention Program Referral Intervention Process Rhode Island: State of Rhode Island, Department of Health; 2016. Available from: http://www.health.ri.gov/publications/brochures/provider/ LeadScreeningAndReferrallnterventionProcess.pdf Access Date: 2018-12-27.

100. Childhood Lead Data and Information South Carolina: S.C. Department of Health and Environmental Control; 2018. Available from: https:/www. scdhec.gov/environment/your-home/lead/childhood-lead-data-andinformation Access Date: 2018-12-27.

101. MEDICAL MICROBIOLOGY — BLOOD LEAD South Dakota: South Dakota Department of Health; 2016. Available from: https://doh.sd.gov/lab/MedicalMicrobiology/lead.aspx Access Date: 2018-12-27.

102. LEAD POISONING (ELEVATED BLOOD LEAD LEVELS) South Dakota: South Dakota Department of Health; 2016. Available from: https://doh.sd.gov/ diseases/infectious/diseasefacts/BloodLead.aspx Access Date: 2018-12-27.

103. Tennessee Childhood Lead Poisoning Prevention Program Screening Guidelines Tennessee: Tennessee Department of Health; 2013. Available from: https:/www.tn.gov/content/dam/tn/health/documents/Lead_ Screening_Guidelines.pdf Access Date: 2018-12-27.

104. Blood Lead Surveillance Branch Texas: Texas Department of State Health Services; 2018. Available from: http://www.dshs.texas.gov/lead/ Access Date: 2018-12-27.

105. Texas Childhood Lead Poisoning Prevention, For Providers Texas: Texas Department of State Health Services; 2018. Available from: http://www.dshs. texas.gov/lead/providers.shtm Access Date: 2018-12-27.

106. Fiks AG, Mayne SL, Michel JJ, et al. Distance-learning, ADHD quality improvement in primary care: a cluster-randomized trial. J Dev Behav Pediatr. 2017. https://doi.org/10.1097/dbp.0000000000000490 PubMed PMID: 28816912. Epub 2017/08/18. eng.

107. Michel J. A technology driven approach for sharing patient-reported outcomes in ADHD between parents, pediatricians and teachers; 2017 .

108. Testing Virginia Children For Lead Exposure Virginia: Virginia Department of Health; 2016. Available from: http://www.vdh.virginia.gov/content/uploads/ sites/20/2017/01/Guidelines-rev-2016.pdf Access Date: 2018-12-27.

109. Regulations for Disease Reporting and Control Virginia: Commonwealth of Virginia State Board of Health; 2016. Available from: http://www.vdh.virginia. gov/content/uploads/sites/13/2016/03/Regulations-for-Disease-Reportingand-Control-October-2016.pdf Access Date: 2018-12-27.

110. Childhood Lead Poisoning Prevention Virginia: Virginia Department of Health; 2017. Available from: http://www.vdh.virginia.gov/leadsafe/ Access Date: 2018-12-27.

111. Lead Screening Recommendations for Children in Washington State Washington: Washington State Department of Health; 2017. Available from: https://www.doh.wa.gov/Portals/1/Documents/Pubs/334-394.pdf Access Date: 2018-12-27.

112. Lead Washington: Washington State Department of Health; 2017. Available from: https://www.doh.wa.gov/CommunityandEnvironment/Contaminants/ Lead Access Date: 2018-12-27.

113. Blood Lead Test Reporting Washington: Washington State Department of Health; 2017. Available from: https://www.doh.wa.gov/

ForPublicHealthandHealthcareProviders/HealthcareProfessionsandFacilities/ ProfessionalResources/BloodLeadTestingandReporting/ BloodLeadTestReporting Access Date: 2018-12-27.

114. Lead-Safe Wisconsin Wisconsin: Wisconsin Department of Health Services; 2018. Available from: https://www.dhs.wisconsin.gov/lead/index.htm Access Date: 2018-12-27.

115. Wisconsin Blood Lead Screening Recommendations Wisconsin: Wisconsin Department of Health Services; 2018. Available from: https://www.dhs. wisconsin.gov/lead/links/wibloodleadscreeningrecommendations.pdf Access Date: 2018-12-27.

116. Ash JS, Sittig DF, Dykstra R, et al. Identifying best practices for clinical decision support and knowledge management in the field. Stud Health
Technol Inform. 2010;160(Pt 2):806-10 PubMed PMID: 20841797. Epub 2010/09/16. eng.

117. Van de Velde S, Kunnamo I, Roshanov P, et al. The GUIDES checklist: development of a tool to improve the successful use of quideline-based computerised clinical decision support. Implement Sci. 2018;13(1):86. https://doi.org/10.1186/s13012-018-0772-3 PubMed PMID: 29941007. PMCID: 6019508. Epub 2018/06/27. eng.

118. Shiffman RN, Dixon J, Brandt C, et al. The GuideLine Implementability appraisal (GLIA): development of an instrument to identify obstacles to guideline implementation. BMC Med Inform Decis Mak. 2005;5(23):1-8. https://doi.org/10.1186/14726947-5-23.

119. Centers for Disease Control and Prevention (CDC). Progress in immunization information systems--United States, 2011. MMWR Morb Mortal Wkly Rep. 2013;62(3):48-51 PubMed PMID: 23344697. Epub 2013/01/25. eng.

120. Curran EA, Bednarczyk RA, Omer SB. Evaluation of the frequency of immunization information system use for public health research. Hum Vaccines Immunother. 2013;9(6) PubMed PMID: 23422024. Epub 2013/02/21. Eng.

121. Butte AJ, Shaw JS, Bernstein H. Strict interpretation of vaccination guidelines with computerized algorithms and improper timing of administered doses. Pediatr Infect Dis J. 2001;20(6):561-5 PubMed PMID: 11419495. Epub 2001/ 06/23. eng.

122. Huser V, Rasmussen LV, Oberg R, et al. Implementation of workflow engine technology to deliver basic clinical decision support functionality. BMC Med Res Methodol. 2011;11:43. https://doi.org/10.1186/1471-2288-11-43 PubMed PMID: 21477364. PMCID: 3079703. Epub 2011/04/12. eng.

123. Karp R, Abramson J, Clark-Golden M, et al. Should we screen for lead poisoning after 36 months of age? Experience in the inner city. Ambul Pediatr. 2001;1(5):256-8 PubMed PMID: 11888411. Epub 2002/03/13. eng.

124. Rischitelli G, Nygren P, Bougatsos C, et al. Screening for elevated lead levels in childhood and pregnancy: an updated summary of evidence for the US preventive services task force. Pediatrics. 2006;118(6):e1867-95. https://doi. org/10.1542/peds.2006-2284 PubMed PMID: 17142507. Epub 2006/12/05. eng.

125. Namli T, Aluc G, Dogac A. An interoperability test framework for HL7-based systems. IEEE Trans Inf Technol Biomed. 2009;13(3):389-99.

126. HL7 Standard: Clinical Quality Language Specification, Release 1 STU3 (CQL 1.3). Health Level Seven International; 2018.

127. Agency for Healthcare Research and Quality (AHRQ). CDS Connect: U.S. Department of Health \& Human Services; 2017. Available from: https://cds. ahrq.gov/ Access Date: 2019-05-01.

128. National Library of Medicine. Value Set Authority Center: National Library of Medicine; 2012 updated 7/16/2016. Available from: https://vsac.nIm.nih.gov/ Access Date: 2019-05-01.

\section{Publisher's Note}

Springer Nature remains neutral with regard to jurisdictional claims in published maps and institutional affiliations.

\section{Ready to submit your research? Choose BMC and benefit from:}

- fast, convenient online submission

- thorough peer review by experienced researchers in your field

- rapid publication on acceptance

- support for research data, including large and complex data types

- gold Open Access which fosters wider collaboration and increased citations

- maximum visibility for your research: over $100 \mathrm{M}$ website views per year

At BMC, research is always in progress.

Learn more biomedcentral.com/submissions 